CLINICAL STUDY

\title{
Genotypes in relation to phenotypic appearance and exposure to environmental factors in Graves' hyperthyroidism
}

\author{
Xander G Vos ${ }^{1}$, Erik Endert ${ }^{2}$, Jan G P Tijssen ${ }^{3}$ and Wilmar M Wiersinga ${ }^{1}$ \\ ${ }^{1}$ Department of Endocrinology and Metabolism, ${ }^{2}$ Laboratory of Endocrinology, Department of Clinical Chemistry and ${ }^{3}$ Department of Cardiology, Academic \\ Medical Center, University of Amsterdam, Meibergdreef 9, 1105 AZ Amsterdam, The Netherlands \\ (Correspondence should be addressed to X G Vos; Email: x.g.vos@amc.nl)
}

\begin{abstract}
Background: Genetic polymorphisms and environmental factors are both involved in the pathogenesis of Graves' disease, but their interaction and effect on Graves' phenotypes have scarcely been investigated.

Objective: To test the hypothesis that subjects with susceptibility genotypes develop more severe Graves' hyperthyroidism at a younger age and after less exposure to environmental factors, with attention to gender differences.

Study design: A prospective observational multicenter study in 205 adult Caucasian patients with untreated first episode of Graves' hyperthyroidism.

Methods: Evaluation of genotypes (HLA DRB1*03, DQA1*05, DQB1*02; CTLA4 49A/G, CT60 A/G; PTPN22 C/T) in relation to phenotypes (age, sex, severity (clinical, biochemical, and immunological)) of hyperthyroidism and environmental factors (smoking, stress questionnaires).

Results: G-alleles in CTLA4 single nucleotide polymorphisms were dose-dependently associated with younger age at the time of diagnosis and less exposure to daily hassles. In gender-specific analysis, this association is enhanced in men and attenuated in women. Males (but not females) in HLA linkage disequilibrium had more severe (biochemical and immunological) hyperthyroidism and a tendency to younger age at diagnosis, compared with those not in linkage disequilibrium.

Conclusion: Graves' hyperthyroidism occurs at a younger age with less exposure to environmental factors in subjects carrying susceptibility genotypes. The impact of genotypes seems to be greater in males than in females.
\end{abstract}

European Journal of Endocrinology 167 783-792

\section{Introduction}

Graves' hyperthyroidism can be considered as a complex multifactorial disease, in which autoimmunity against thyroid antigens develops against a particular genetic background provoked by environmental factors $(1,2)$. Good quantitative evidence that genetic factors play an important role in the etiology of Graves' hyperthyroidism is derived from twin studies, showing significantly higher probandwise concordance rates in monozygotic twins than in dizygotic twins $(3,4,5)$. Using structural equation modeling, the heritability of Graves' disease has been reported to be $79 \%$ (95\% CI, $38-90 \%)$ (6). It means the relative impact of genetic factors is around $75 \%$; consequently, the relative contribution of environmental factors would be around $25 \%$.

Genes shown to confer susceptibility to Graves' disease can be divided into thyroid-specific genes (TSHR, TG) and immune regulatory genes (HLA, CTLA4, PTPN22, CD4O, FOXP3, IL2RA, FCRL3).
Known environmental factors that may induce Graves' disease are smoking, stress, iodine intake, pregnancy, and drugs such as interferon and highly active anti-retroviral therapy.

So far, genetic and environmental factors contributing to Graves' disease have been studied mostly separately from each other. The aims of the present study in patients with newly diagnosed Graves' hyperthyroidism were therefore as follows. First, we evaluated whether specific genotypes are associated with differences in the clinical presentation of Graves' hyperthyroidism. We hypothesized that subjects with genetic susceptibility to Graves' disease might be younger at the time of diagnosis and presenting with more severe disease. Second, we evaluated the relationship between specific genotypes and exposure to environmental factors. We hypothesized that subjects with genetic susceptibility to Graves' disease might require less exposure to environmental factors for contracting Graves' hyperthyroidism. Special attention was given to possible differences in gender; in view of the 
strong female preponderance in autoimmune thyroid disease, the development of Graves' disease in males might require a much heavier load of either susceptibility genes or exposure to environmental factors.

Both hypotheses were tested in a prospective observational study of consecutive patients with untreated first episode of Graves' hyperthyroidism. Genotypes and phenotypes were assessed as well as exposure to a number of environmental factors.

\section{Materials and methods}

\section{Patients}

We included consecutive untreated patients with a first episode of Graves' hyperthyroidism in a prospective, multicenter, observational study. Patients were included from one university and eight city hospitals in The Netherlands. Inclusion criteria were: biochemical hyperthyroidism (TSH $<0.4 \mathrm{mU} / \mathrm{l}$; thyroxine (free $\left.\mathrm{T}_{4}\left(\mathrm{fT}_{4}\right)\right)>23 \mathrm{pmol} / \mathrm{l}$; and/or triiodothyronine $\left(\mathrm{T}_{3}\right)$ $>2.7 \mathrm{nmol} / \mathrm{l}$ ) and a diffuse homogeneous uptake on thyroid scintigraphy $\left({ }^{99 \mathrm{~m}} \mathrm{Tc}\right.$-pertechnetate). Exclusion criteria were: relapse of Graves' disease; no written informed consent; no understanding of the Dutch language; and alcohol or drug abuse. As described previously, 263 patients were assembled satisfying the inclusion and exclusion criteria (7). For the present study, we excluded 51 patients because of non-Caucasian origin and seven patients because no DNA samples were obtained, leaving a study population of 205 patients.

Clinical parameters were recorded including goiter size (8), the existence of Graves' orbitopathy and pretibial myxedema, and the Hyperthyroid Symptom Scale (HSS) (9). Participants were asked to complete questionnaires asking about smoking habits and stress at the time of diagnosis as published previously $(7,10)$. Smoking habits were assessed as current smokers, ex-smokers, and never smokers. The Dutch questionnaire on recently experienced stressful life events counts the total number of major life events experienced in the last 12 months (checklist of 60 possible events); the amount of pleasantness and unpleasantness with each experienced life event is rated on a scale of 0 (meaning no (un)pleasantness) to 4 (meaning a huge amount of (un)pleasantness), and the total amount of pleasantness and unpleasantness is calculated (maximum score 240 for each) (11). The Dutch Everyday Problem Checklist is a validated version of the Daily Hassles Scale, and consists of 114 items concerning daily hassles in the last 2 months; it also measures the intensity of each hassle on a scale from 0 to 3 , yielding the total intensity of daily hassles (maximum score 342$)(12,13)$. The Positive and Negative Affect Schedule (PANAS) measures the current mood in terms of positive and negative affect; it consists of 22 mood states (11 positive, 11 negative) rated on a scale from 1 (not at all) to 5 (a lot), yielding the tendency to report positive and negative feelings both on a scale from 11 to 55 (14). The study was approved by the Institutional Review Board of the Academic Medical Center of Amsterdam and the eight other participating centers. All patients gave written informed consent.

\section{Laboratory measurements}

Non-fasting venous blood samples were taken for thyroid function tests and thyroid autoantibody measurements before treatment was started; storage was at $-20{ }^{\circ} \mathrm{C}$ until assay. Serum $\mathrm{T}_{3}$ and $\mathrm{T}_{4}$ were measured with in-house RIAs (15). $\mathrm{T}_{3}$ uptake was determined by a no-extraction, solid-phase ${ }^{125}$ I-RIA (Coat-A-Count; Diagnostic Products Corporation, Los Angeles, CA, USA). Free $\mathrm{T}_{4}$ index and free $\mathrm{T}_{3}$ index were calculated by multiplying $\mathrm{T}_{3}$ uptake with $\mathrm{T}_{4}$ and $\mathrm{T}_{3}$ respectively (reference ranges $70-140$ and 3.3-8.2 respectively). Serum TSH was determined with a fluoroimmunometric assay (Delfia hTSH; Perkin Elmer, Turku, Finland; detection limit $0.01 \mathrm{mU} / \mathrm{l}$, reference range $0.4-4.0 \mathrm{mU} / \mathrm{l})$. Serum TSH-binding inhibitory immunoglobulin (TBII) was determined by a secondgeneration luminescence receptor assay (TRAK human LIA; B.R.A.H.M.S., Berlin, Germany; detection limit $1.0 \mathrm{IU} / \mathrm{l}$, reference range <2.0 IU/l). Autoantibodies against thyroid peroxidase (TPO-Ab) were analyzed by anti-TPO LIA (B.R.A.H.M.S.; detection limit $30 \mathrm{kU} / \mathrm{l}$, reference range $<60 \mathrm{kU} / \mathrm{l})$. All measurements were performed at the laboratory of the Academic Medical Center of Amsterdam.

\section{Genotyping}

Genomic DNA was isolated from peripheral blood leukocytes using the MagNA Pure apparatus and the MagNA Pure LC DNA Isolation Kit (Roche Biochemicals) according to the manufacturer's protocol. Genomic amplifications were obtained by the PCR using the TGradient Thermocycler (Biometra, Göttingen, Germany). CTLA4 49A/G (rs231775) and CTLA4 CT60 (rs3087243) single nucleotide polymorphisms (SNPs) were detected using primers as described before (16). The SNP in PTPN22 (rs2476601) was detected using previously described primers (17). The PCR was performed in a volume of $50 \mu \mathrm{l}$ containing $1.5 \mathrm{mM}$ $\mathrm{MgCl}_{2}, 0.5 \mathrm{mM}$ dNTPs, $50 \mathrm{ng}$ genomic DNA, $0.2 \mu \mathrm{M}$ of each primer, and 2.5 U AmpliTaq Gold DNA polymerase (Applied Biosystems, Foster City, CA, USA). The PCR products were separated by a $2 \%$ agarose gel electrophoresis and identified by ethidium bromide staining. The same primers were used for PCR amplification and sequencing. Cyclic sequencing reactions were performed using the BigDye Terminator v1.1 Cycle Sequencing Kit (Applied Biosystems), and the sequencing products purified using the Agencourt CleanSEQ Kit (GC Biotech, Schiedam, The Netherlands). 
Sequencing was performed using the Hitachi 3730 DNA Analyzer (Applied Biosystems). Sequence analysis was done using Sequencing Analysis 5.1 and CodonCode Aligner 5.2.1 programs.

HLA subtypes (DQB1*02, DQA1*05, DRB1*03) were identified on a LightCycler 480 (Roche Molecular Diagnostics) using the LightCycler 480 High Resolution Melting Master (Roche Molecular Diagnostics) according to the manufacturer's protocol. Primer sequences were as described before for DQB1*02 (18), DQA1*05 (19), and DRB1*03 $(18,20)$.

\section{Statistical analysis}

$\chi^{2}$ tests, $t$-tests, and non-parametric tests were used for comparison of proportions, means, and medians between HLA-positive and -negative patients and PTPN22 heterozygote polymorphism and wild type. The same tests were used for comparison between A-alleles and G-alleles in male and female patients for the CTLA4 49A/G and CTLA4 CT60 polymorphisms. Trend analysis between the allele frequencies of the CTLA4 49A/G and CTLA4 CT60 polymorphisms for age, serum TBII, serum TPO-Ab, and different stress scores was performed using the Jonckheere-Terpstra test. A comparison of serum free $\mathrm{T}_{3}$ index and free $\mathrm{T}_{4}$ index and a comparison of proportions between these groups was done using linear regression analysis and $\chi^{2}$ tests respectively. $P$ values $<0.05$ indicated statistical significance. Statistical analyses were carried out using the SPSS statistical package for Windows, version 18.0 (SPSS, Inc., Chicago, IL, USA).

\section{Results}

\section{Characteristics of the study population}

The mean age of the 205 patients was 43.5 years (range 16.4-80.0 years). There were 55 males and 150 females. Free $\mathrm{T}_{3}$ indices were $7.0 \pm 3.8$ and free $\mathrm{T}_{4}$ indices were $333 \pm 128$ (mean \pm s.D.), serum TBII concentrations were 8.9 (5.0-18.6 IU/l), and TPO-Ab were $420(40-2610 \mathrm{kU} / \mathrm{l})$ (median values with interquartile ranges). Goiter size was grade 0 in $67 \%$, grade I in $18 \%$, grade II in $11 \%$, and grade III in $4 \%$ of patients. Graves' orbitopathy was present in $20 \%$ and pretibial myxedema in $5 \%$. The hyperthyroid symptom score was $15.1 \pm 7.1$ (mean \pm s.D.). None of the patients was pregnant, but $67 \%$ of women had been pregnant in the past. Oral contraceptives were used by $27 \%$. There were $38 \%$ current smokers, $29 \%$ ex-smokers, and 33\% never smokers. The prevalence of particular genotypes was as follows: HLA DRB1*03, 63\%; HLA DQA1*05, 73\%; HLA DQB1*02, 61.5\%; CTLA4 49A/G, heterozygotes $49.5 \%$, homozygotes 13\%; CTLA4 CT60, heterozygotes $51 \%$, homozygotes $32.5 \%$; PTPN22 C/T, heterozygotes $28 \%$, homozygotes $0 \%$.

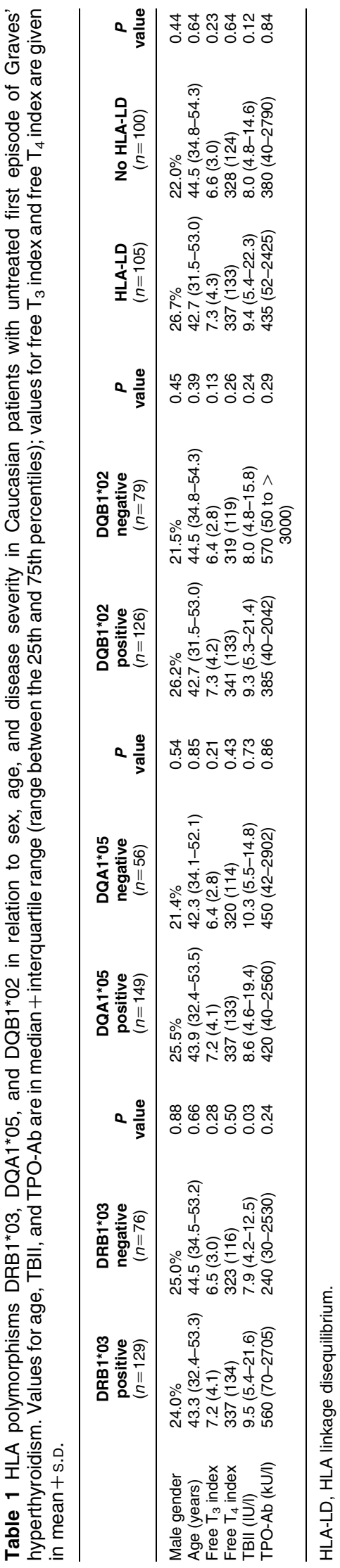

www.eje-online.org 
Table 2 Gender-specific analysis of age at diagnosis, disease severity, and environmental exposure according to the presence of HLA linkage disequilibrium (HLA-LD) in Caucasian patients with untreated first episode of Graves' hyperthyroidism. Values for age, TBII, TPO$A b$, and daily hassles are in median + interquartile range (range between the 25th and 75th percentiles); values for free $T_{3}$ index and free $T_{4}$ index are given in mean + S.D.

\begin{tabular}{|c|c|c|c|c|c|c|}
\hline & \multicolumn{3}{|c|}{ Male } & \multicolumn{3}{|c|}{ Female } \\
\hline & $\begin{array}{l}\text { HLA-LD } \\
(n=28)\end{array}$ & $\begin{array}{l}\text { No HLA-LD } \\
(n=22)\end{array}$ & $P$ value & $\begin{array}{r}\text { HLA-LD } \\
(n=78)\end{array}$ & $\begin{array}{l}\text { No HLA-LD } \\
\quad(n=77)\end{array}$ & $P$ value \\
\hline Age (years) & $41.5(32.2-55.8)$ & $45.5(39.0-56.0)$ & 0.38 & $43.0(30.0-52.0)$ & $43.5(31.8-53.0)$ & 0.87 \\
\hline Free $T_{3}$ index & $8.9(6.2)$ & $6.0(2.2)$ & 0.035 & 6.7 (3.3) & $6.8(3.2)$ & 0.86 \\
\hline Free $\mathrm{T}_{4}$ index & $368(140)$ & $294(93)$ & 0.051 & $325(129)$ & $338(130)$ & 0.57 \\
\hline TBII (IU/I) & $10.0(6.0-24.2)$ & $8.2(4.0-17.4)$ & 0.26 & $9.3(5.1-21.4)$ & $8.0(4.7-14.5)$ & 0.29 \\
\hline TPO-Ab (kU/l) & 725 (170-2956) & $90(<30$ to 1980$)$ & 0.02 & $355(40-1600)$ & $540(80-2970)$ & 0.13 \\
\hline Current smokers & $35 \%$ & $57 \%$ & 0.12 & $36 \%$ & $37 \%$ & 0.87 \\
\hline \multicolumn{7}{|l|}{ Daily hassles } \\
\hline $\begin{array}{l}\text { Total number of daily } \\
\text { hassles }\end{array}$ & $18(13-28)$ & $26(9-35)$ & 0.62 & $20(10-32)$ & $20(11-32)$ & 0.79 \\
\hline Intensity per hassle & $1.4(0.9-1.6)$ & $1.7(1.3-1.9)$ & 0.02 & $1.5(1.2-1.8)$ & $1.6(1.2-2.0)$ & 0.28 \\
\hline $\begin{array}{l}\text { Total intensity of all } \\
\text { hassles }\end{array}$ & $27(11-40)$ & $36(11-60)$ & 0.35 & $30(14-56)$ & $29(16-58)$ & 0.98 \\
\hline
\end{tabular}

HLA-LD, HLA linkage disequilibrium.

\section{HLA genotypes}

The HLA polymorphisms DRB $1 * 03$, DQA $1 * 05$, and DQB1*02 were not associated with gender, age, biochemical severity (free $\mathrm{T}_{3}$ and free $\mathrm{T}_{4}$ indices), or immunological severity (TBII and TPO-Ab), with the single exception of a slightly higher TBII in DRB $1^{*} 03$-positive patients (Table 1 ). Neither were there associations with the clinical severity of Graves' hyperthyroidism (goiter size, Graves' orbitopathy, pretibial myxedema, hyperthyroid symptom score), nor with smoking and scores on the three stress questionnaires (data not shown). The HLA genotypes were in strong linkage disequilibrium $(P<0.01)$, but no differences in any parameter were observed between patients with and without HLA linkage disequilibrium (Table 1). When this analysis was done separately for each gender, the outcome was the same in females (no differences between the 78 women with and the 77 women without HLA linkage disequilibrium) but slightly different in males (Table 2). Men with HLA linkage disequilibrium had more severe biochemical

Table 3 Relationship between the CTLA4 49A/G polymorphism and sex, age, disease severity, and environmental exposure in Caucasian patients with untreated first episode of Graves' hyperthyroidism. Values for age, TSH, TBII, TPO-Ab, and stress scores are in median + interquartile range (range between the 25th and 75th percentiles); values for HSS-score, free $T_{3}$ index, and free $T_{4}$ index are given in mean + S.D.

\begin{tabular}{|c|c|c|c|c|}
\hline & $\begin{array}{l}\text { A/A wild type } \\
\quad(n=76)\end{array}$ & $\begin{array}{l}\text { A/G heterozygote } \\
\qquad(n=100)\end{array}$ & $\begin{array}{c}\text { G/G homozygote } \\
\qquad(n=25)\end{array}$ & $P$ value \\
\hline Male gender & $25 \%$ & $23 \%$ & $31 \%$ & 0.74 \\
\hline Age (years) & $47.5(38.0-57.0)$ & $41.0(31.0-50.8)$ & $40.5(29.8-46.2)$ & $<0.01$ \\
\hline Free $\mathrm{T}_{3}$ index & $6.7(2.7)$ & $7.2(4.5)$ & $7.2(3.6)$ & 0.47 \\
\hline Free $\mathrm{T}_{4}$ index & $331(124)$ & $331(134)$ & $344(131)$ & 0.76 \\
\hline TBII (IU/I) & $7.7(4.5-14.1)$ & $9.9(5.4-18.8)$ & $10.4(3.5-24.0)$ & 0.10 \\
\hline TPO-Ab (kU/l) & $365(40-2652)$ & $395(48-2260)$ & $1310(105-2903)$ & 0.34 \\
\hline Current smokers & $36 \%$ & $42 \%$ & $36 \%$ & 0.71 \\
\hline \multicolumn{5}{|l|}{ Stress scores } \\
\hline \multicolumn{5}{|l|}{ PANAS } \\
\hline Tendency to report negative feelings & $22(17-29)$ & $22(17-28)$ & $24(16-28)$ & 0.65 \\
\hline Tendency to report positive feelings & $37(32-41)$ & $37(33-40)$ & $38(34-42)$ & 0.36 \\
\hline \multicolumn{5}{|l|}{ Daily hassles } \\
\hline Total number of daily hassles & $21(14-35)$ & $20(10-30)$ & $15(6-28)$ & 0.08 \\
\hline Intensity per hassle & $1.7(1.3-2.0)$ & $1.6(1.2-1.8)$ & $1.4(0.8-1.7)$ & $<0.01$ \\
\hline Total intensity of all hassles & $38(20-60)$ & $28(14-54)$ & $17(6-46)$ & 0.02 \\
\hline \multicolumn{5}{|l|}{ Recent life events } \\
\hline Total number of life events & $8(5-14)$ & $9(5-14)$ & $6(4-12)$ & 0.44 \\
\hline Number of unpleasant events & $5(3-9)$ & $5(2-8)$ & $3(1-6)$ & 0.13 \\
\hline Number of pleasant events & $2(1-5)$ & $2(1-5)$ & $3(1-5)$ & 0.80 \\
\hline Amount of total unpleasantness & $16(7-33)$ & $15(7-28)$ & $11(4-19)$ & 0.17 \\
\hline Amount of total pleasantness & $9(4-17)$ & $10(4-17)$ & $8(4-20)$ & 0.97 \\
\hline
\end{tabular}




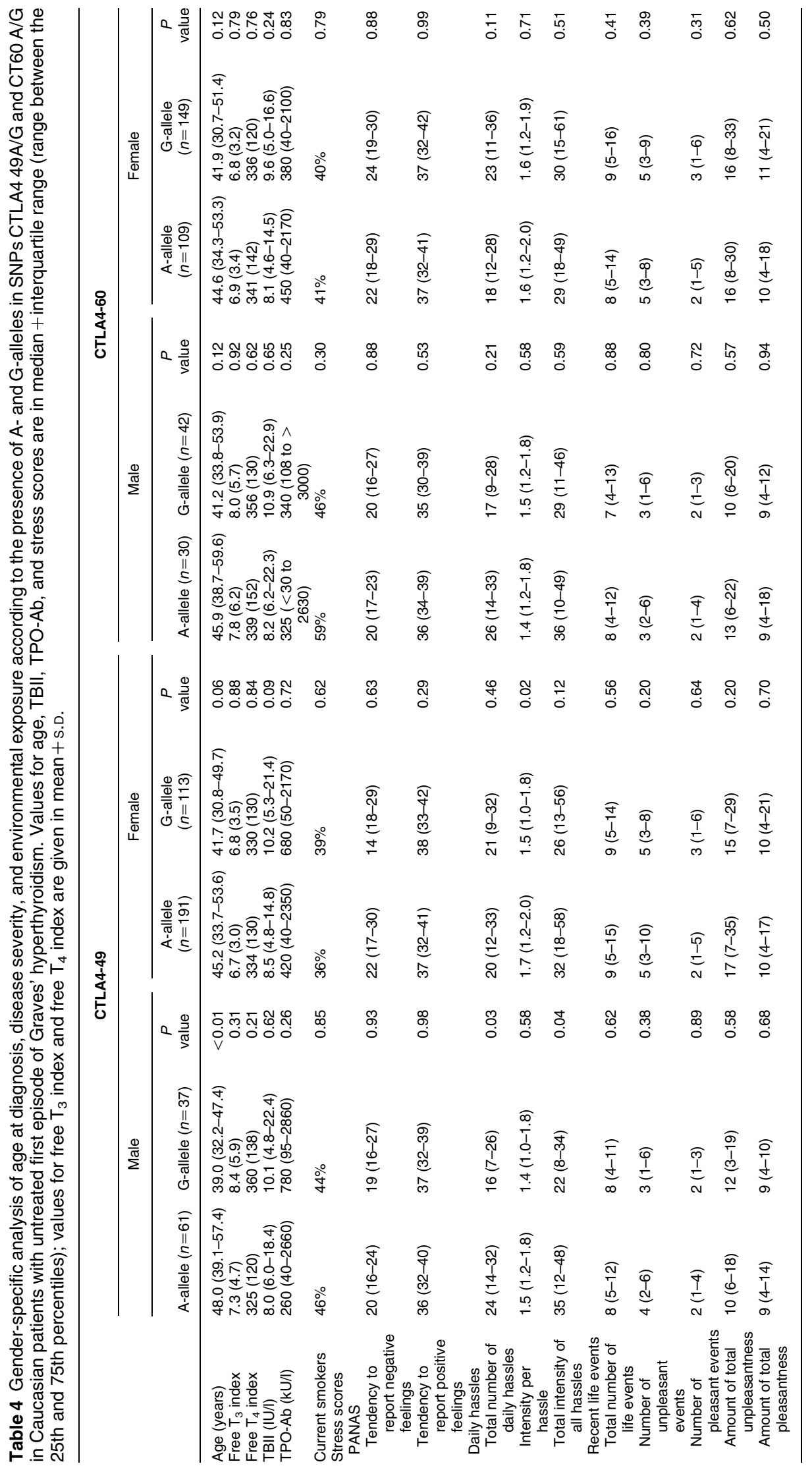


and immunological hyperthyroidism by means of higher serum free $\mathrm{T}_{3}$ index $(P=0.035)$, free $\mathrm{T}_{4}$ index $(P=0.051)$, and TPO-Ab $(P=0.02)$ compared with men without HLA linkage disequilibrium (Table 2). The number of current smokers was non-significantly lower in the linkage disequilibrium group (35 vs $57 \%$, $P=0.12$ ). According to the stress scores, the intensity per hassle was lower in men with HLA linkage disequilibrium $(P=0.02)$ while the total intensity of all hassles did not differ $(P=0.35)$. The data suggest more severe Graves' hyperthyroidism and less daily hassles in males (but not in females) in whom HLA class II genes are in linkage disequilibrium.

\section{CTLA4 genotypes}

Table 3 lists the associations with the CTLA4 49A/G polymorphism. Whereas gender distribution was similar between the three genotypes, age at diagnosis of Graves' hyperthyroidism decreased progressively with increasing number of G-alleles. G/G homozygotic patients were 7 years younger when presenting with Graves' hyperthyroidism compared with wild-type patients. Biochemical, immunological, and clinical severity were not related to the number of G-alleles, although there was a non-significant trend towards higher TBII and TPO-Ab concentrations in homozygotes. Goiter size also tended to be larger in the presence of G-alleles (goiter size grade 0 and grades $\geq \mathrm{I}$ were 74 and $26 \%$ respectively in wild type, 67 and 33\% in heterozygotes, and 54 and $46 \%$ in homozygotes, $P$ for trend $=0.088$ ). No associations were found with exposure to environmental factors, except exposure to stress. Trend analysis indicated progressively less daily hassles with increasing number of G-alleles.

We further analyzed the CTLA4 49A/G polymorphism by comparing patients with A-alleles and patients with G-alleles separately for each gender (Table 4). In males, the presence of G-alleles was associated with younger age at the time of diagnosis ( 9 years difference) and less exposure to daily hassles. In females, the presence of G-alleles was slightly related to younger age at diagnosis of Graves' hyperthyroidism (3.5 years difference, just failing to reach statistical significance with a $P$ value of 0.06 ), but not to the number of daily hassles or the total intensity of all hassles (only the intensity per hassle was lower).

Table 5 presents the associations with the CTLA4 CT60 polymorphism, which were available in 165 patients. Trend analysis showed younger age at the time of diagnosis with increasing number of G-alleles: homozygotes were 8 years younger when compared with wild-type patients. No other associations were found, neither in biochemical, immunological, or clinical severity of Graves' hyperthyroidism, nor in gender and exposure to environmental factors. Table 4 contrasts patients with A-alleles and patients with G-alleles according to gender. Male patients with G-alleles were on average 4.7 years younger at the time of diagnosis, but the difference in age with A-allele patients was not significant $(P=0.12)$. Female patients with G-alleles were also non-significantly 2.7 years younger at the time of diagnosis $(P=0.12)$. No other associations were observed, neither in males nor in females.

Table 5 Relationship between the CTLA4 CT60 A/G polymorphism and sex, age, disease severity, and environmental exposure in Caucasian patients with untreated first episode of Graves' hyperthyroidism. Values for age, TBII, TPO-Ab, and stress scores are in median + interquartile range (range between the 25th and 75th percentiles); values for free $T_{3}$ index and free $T_{4}$ index are given in mean+S.D.

\begin{tabular}{|c|c|c|c|c|}
\hline & $\begin{array}{l}\text { A/A wild type } \\
\quad(n=27)\end{array}$ & $\begin{array}{c}\text { A/G heterozygote } \\
\qquad(n=85)\end{array}$ & $\begin{array}{c}\text { G/G homozygote } \\
\qquad(n=53)\end{array}$ & $P$ value \\
\hline Male gender & $18 \%$ & $23 \%$ & $22 \%$ & 0.79 \\
\hline Age (years) & $46.0(38.0-57.0)$ & $43.0(33.0-51.5)$ & $38.0(30.0-51.0)$ & 0.04 \\
\hline Free $T_{3}$ index & $7.3(3.3)$ & $7.0(4.6)$ & $7.1(3.2)$ & 0.88 \\
\hline Free $\mathrm{T}_{4}$ index & $343(146)$ & $339(144)$ & $339(105)$ & 0.91 \\
\hline TBII (IÜ/I) & $7.2(4.2-10.5)$ & $9.8(5.4-19.4)$ & $10.1(4.9-18.4)$ & 0.28 \\
\hline TPO-Ab (kU/l) & $520(<30$ to 2870$)$ & $260(40-1820)$ & $565(108-2955)$ & 0.37 \\
\hline Current smokers & $56 \%$ & $38 \%$ & $43 \%$ & 0.48 \\
\hline \multicolumn{5}{|l|}{ Stress scores } \\
\hline \multicolumn{5}{|l|}{ PANAS } \\
\hline Tendency to report negative feelings & $23(20-31)$ & $21(16-27)$ & $24(19-30)$ & 0.71 \\
\hline Tendency to report positive feelings & $37(33-41)$ & $36(33-40)$ & $37(30-42)$ & 0.83 \\
\hline \multicolumn{5}{|l|}{ Daily hassles } \\
\hline Total number of daily hassles & $18(12-32)$ & $19(12-28)$ & $26(9-37)$ & 0.43 \\
\hline Intensity per hassle & $1.7(1.2-2.0)$ & $1.5(1.2-1.8)$ & $1.6(1.2-1.9)$ & 0.90 \\
\hline Total intensity of all hassles & $33(18-55)$ & $28(14-48)$ & $29(14-69)$ & 0.78 \\
\hline \multicolumn{5}{|l|}{ Recent life events } \\
\hline Total number of life events & $11(6-15)$ & $7(4-12)$ & $9(5-17)$ & 0.50 \\
\hline Number of unpleasant events & $4(3-9)$ & $4(2-7)$ & $5(3-10)$ & 0.46 \\
\hline Number of pleasant events & $3(2-6)$ & $2(1-3)$ & $3(1-6)$ & 0.26 \\
\hline Amount of total unpleasantness & $20(12-35)$ & $13(6-22)$ & $17(8-39)$ & 0.79 \\
\hline Amount of total pleasantness & $10(7-24)$ & $8(4-13)$ & $13(4-23)$ & 0.56 \\
\hline
\end{tabular}


Table 6 Relationship between the PTPN22 C/T polymorphism and sex, age, disease severity, and environmental exposure in Caucasian patients with untreated first episode of Graves' hyperthyroidism. Values for age, TBII, TPO-Ab, and stress scores are in median+ interquartile range (range between the 25th and 75th percentiles); values for free $T_{3}$ index and free $T_{4}$ index are given in mean + S.D.

\begin{tabular}{|c|c|c|c|}
\hline & PTPN22 C/C $(n=147)$ & PTPN22 C/T $(n=58)$ & $P$ value \\
\hline Male gender & $24 \%$ & $24 \%$ & 0.96 \\
\hline Age (years) & $44.0(33.7-53.2)$ & $41.0(31.1-53.2)$ & 0.58 \\
\hline Free $\mathrm{T}_{3}$ index & $6.9(3.7)$ & $7.0(3.9)$ & 0.89 \\
\hline Free $\mathrm{T}_{4}$ index & $341(136)$ & $313(104)$ & 0.18 \\
\hline TBII (IU/I) & $8.9(4.8-18.5)$ & $9.0(5.4-18.9)$ & 0.86 \\
\hline TPO-Ab (kU/l) & $330(40-1795)$ & $710(58$ to $>3000)$ & 0.12 \\
\hline Current smokers & $38 \%$ & $39 \%$ & 0.94 \\
\hline \multicolumn{4}{|l|}{$\begin{array}{l}\text { Stress scores } \\
\text { PANAS }\end{array}$} \\
\hline Tendency to report negative feelings & $22(17-29)$ & $21(17-27)$ & 0.41 \\
\hline Tendency to report positive feelings & $36(32-40)$ & $40(35-42)$ & $<0.01$ \\
\hline \multicolumn{4}{|l|}{ Daily hassles } \\
\hline Total number of daily hassles & $20(10-32)$ & $21(12-30)$ & 0.73 \\
\hline Intensity per hassle & $1.6(1.2-1.9)$ & $1.6(1.2-1.8)$ & 0.64 \\
\hline Total intensity of all hassles & $29(14-56)$ & $29(13-49)$ & 0.91 \\
\hline \multicolumn{4}{|l|}{ Recent life events } \\
\hline Total number of life events & $8(5-14)$ & $9(5-12)$ & 0.78 \\
\hline Number of unpleasant events & $5(3-9)$ & $4(2-7)$ & 0.35 \\
\hline Number of pleasant events & $2(1-4)$ & $3(1-6)$ & 0.07 \\
\hline Amount of total unpleasantness & $15(7-31)$ & $14(8-25)$ & 0.68 \\
\hline Amount of total pleasantness & $9(4-14)$ & $11(5-23)$ & 0.06 \\
\hline
\end{tabular}

\section{PTPN22 genotypes}

Table 6 compares patients with wild-type PTPN22 C/C and patients with PTPN22 C/T (heterozygotes). No differences between the two groups were observed, with the exception that heterozygotes had a greater tendency to report positive feelings $(P=0.008)$ and had experienced a greater number of pleasant events $(P=0.07)$ and a higher amount of total pleasantness $(P=0.06)$. The greater tendency to report positive feelings in the presence of a T-allele was stronger in males $(P=0.009)$ than in females $(P=0.081)$.

\section{Discussion}

The investigated genetic variants in HLA, CTLA4, and PTPN22 all carry a risk for Graves' disease $(21,22)$. The variants cause abnormalities in antigen presentation and T-cell activation in the immunological synapse, thus playing a significant role in the etiology of Graves' disease (23). The observed frequencies of genetic variants in our population of patients with Graves' hyperthyroidism are in good agreement with figures reported in other studies in adult Caucasian patients with Graves' disease. The corresponding frequencies in the present study and in the literature are respectively: for HLA, DRB1*0304 63\% and 47-48\%, DQB1*02 61\% and $58-59 \%$, DQA $1 * 050173 \%$ and $63-67 \%$, haplotype DRB1*304-DQB1*02-DQA1*0501 51\% and 47\% (24, 25); for CTLA4 49A/G, AA 37.8\% and 27-39\%, AG $49.8 \%$ and $45-59 \%$, GG $12.4 \%$ and $14-25 \%$, A-alleles $63 \%$ and $52-57 \%$, G-alleles $37 \%$ and $44-48 \%$ (25, 26, 27, 28, 29); for CTLA4 CT60, AA $16.4 \%$ and $13-17 \%$, AG $51.5 \%$ and $46-53 \%$, GG $32.1 \%$ and
$30-41 \%$, A-alleles $42 \%$ and $36-44 \%$, G-alleles $58 \%$ and $56-64 \%(28,29)$; for PTPN22 C/T, CC 72\% and 65-74\%, CT $28 \%$ and $25-31 \%$, TT $0 \%$ and $1-4 \%$, C-alleles $86 \%$ and $81-86 \%$, T-alleles $14 \%$ and $14-19 \%(17,30)$.

The well-known linkage disequilibrium between Graves' disease and genes in the HLA class II region, also observed in our study, is due to the extended haplotype DRB1*304-DQB1*02-DQA1*501 (24). It indicates a lack of independent associations of each allele with Graves' disease; the primary susceptibility gene, however, might well be DRB1*03 (23). The two SNPs CTLA4 49A/G and CTLA4 60CT are in the same haplotype block and also in linkage disequilibrium $(28,29,31,32)$. The occurrence of SNPs in CTLA4 is independent of the presence of DRB $1^{*} 03$ (28). Likewise, the frequency of the PTPN22 C/T variant is independent of DRB1*03 and CTLA4 49A/G (30). Thus, the genetic variants in HLA, CTLA4, and PTPN22 are independent risk factors for Graves' disease (16).

\section{Genotypes in relation to phenotypes}

We observed a significant younger age at the time of diagnosis of Graves' hyperthyroidism in patients with SNPs in CTLA4, both in 49A/G and 60CT A/G genotypes. The G-allele of both SNPs increases the odds for Graves' disease (31), and a dose-response effect for the G-allele was found by trend analysis: G/G homozygotes were the youngest. We did not find a relationship between the age of onset and the genetic variants in HLA class II and PTPN22. Our data are at variance with a Polish study in adult Caucasian patients with Graves' hyperthyroidism, which observed no relationship between the age of onset and HLA variants or CTLA4 49A/G but patients with 
G-alleles of the PTPN22 SNP were 10 years younger (30). The age difference in our cohort is in the same range: 7 years for the difference between homozygotes and the wild type of CTLA4 49A/G, and 8 years for that of CTLA4 CT60. These values are in the same order of magnitude when the age of onset is related to a family history of thyroid disease (33). A positive family history is associated with a younger age of onset when compared with no family history (difference: 6 years in males and 5 years in females) (34). Interestingly, there are no significant differences between the frequencies of HLA class II polymorphisms and the susceptibility alleles of CTLA4 49A/G and CT60 SNPs in the familial and sporadic cases of Graves' disease, suggesting that additional genes must contribute to the aggregation of Graves' disease within families (16).

The distribution of gender was similar in patients with or without the investigated genetic variants, in agreement with previous studies $(30,32)$. We also did not observe a relationship between genotypes and biochemical, immunological, or clinical severity of Graves' hyperthyroidism, with the single exception that males in HLA linkage disequilibrium had more severe (biochemical and immunological) hyperthyroidism than males without HLA linkage disequilibrium; this was not observed in females. We could not find comparative data on this topic in the literature. There are just a few studies reporting the absence of a relationship between HLA class II, CTLA4, or PTPN22 variants and the presence of Graves' ophthalmopathy $(27,30,32,35)$. In summary, phenotypic appearance of Graves' hyperthyroidism in our study did not differ between the genotypes, but the age at diagnosis was significantly younger in carriers of G-alleles in CTLA4 polymorphisms.

\section{Genotypes in relation to environmental factors}

The proportion of current smokers did not differ between patients with or without the genetic variants in HLA, CTLA4, or PTPN22. In contrast, the polymorphism CTLA4 49A/G (but none of the other genotypes) was quantitatively related to stress exposure. The total number of daily hassles, the intensity per hassle, and the total intensity of daily hassles were all lower in carriers of the G-allele of this polymorphism in a dose-dependent manner. The CTLA4 49A/G SNP was not related to mood (PANAS scales) or to recent life events. According to psychological studies, everyday exposure to daily hassles in general constitutes a greater burden of stressors than incidental exposure to major life events $(12,36)$. The observation of less daily hassles is not biased by mood changes in our study (current mood state may influence the perception and thereby the scores of daily hassles and recent life events) $(12,36)$. Less daily hassles in carriers of G-alleles of CTLA4 49A/G can also not be explained by their lower age, as recent studies have shown a progressive decrease in daily hassles with advancing age in healthy subjects with highest scores occurring in the youngest age groups of $<40$ years (37). The finding that SNP CTLA4 $49 \mathrm{~A} / \mathrm{G}$ is associated with younger age at diagnosis and with less exposure to stress supports our preformulated hypothesis that subjects with genetic susceptibility to Graves' disease might require less exposure to environmental factors for contracting Graves' hyperthyroidism. A literature search did not reveal other studies relating genetic variants in HLA, CTLA4, and PTPN22 to environmental factors, apart from the notion that the frequency of tobacco smoking was not related to the SNP in PTPN22 (30).

\section{Genotypes in relation to gender}

Subset analysis has been shown to be a powerful method to dissect the roles of 'weak' susceptibility genes in complex diseases: weak susceptibility genes may have a stronger effect in a particular subset of patients (23). Because the median age at diagnosis of Graves' disease is lower in women than in men, and younger age is associated with more severe hyperthyroidism (higher serum $\mathrm{FT}_{4}$ ) (34), we performed a subset analysis according to gender.

Comparing women with and without HLA linkage disequilibrium, no differences were found. However, men with HLA linkage disequilibrium had more severe (biochemical and immunological) hyperthyroidism and a lower intensity per hassle. Furthermore, the amount of current smokers in men with HLA linkage disequilibrium was lower (35 vs $57 \%, P=0.12$ ) and their age at diagnosis was 4 years lower than males not in linkage disequilibrium. The difference was not significant most likely due to the small sample size of males.

With regard to CTLA4 49A/G, male carriers of a G-allele had a lower age at diagnosis and less daily hassles; their values of free $\mathrm{T}_{4}$ index, free $\mathrm{T}_{3}$ index, TBII, and TPO-Ab were - albeit not significantly - higher. These associations were much weaker in female carriers of G-alleles (despite the greater sample size of females) but the trend was in the same direction. Female patients carrying a G-allele were 3.5 years younger at the time of diagnosis compared with A-allele carriers $(P=0.06)$.

Evaluation of the SNP CTLA4 CT60 according to gender did not disclose new findings; the lower age at diagnosis in the presence of G-alleles was non-significantly observed in both sexes $(P=0.12)$. For the SNP PTPN22 C/T, the age at diagnosis in males was 5 years lower in heterozygotes than in the wild type but the difference was not significant, whereas the age in females was not dependent on G-alleles (data not shown).

Gender-specific analysis thus disclosed that the association of CTLA4 $49 \mathrm{~A} / \mathrm{G}$ with younger age at diagnosis and less daily hassles was maintained in males but lost in females. Furthermore, males in HLA linkage disequilibrium had more severe (biochemical and immunological) hyperthyroidism, and tended to be younger at diagnosis and less exposed to tobacco 
smoking and hassles; this was not observed in females. Because the proportion of patients with HLA linkage disequilibrium and that of patients with G-alleles of CTLA4 SNPs did not differ between males and females, the conclusion seems warranted that the impact of susceptibility genes is greater in males than in females. It follows that the role of environmental factors in the pathogenesis of Graves' disease might be relatively greater in females than in males.

\section{Strengths and limitations}

The main strength of the present study is its prospective nature, allowing simultaneous assessment in each patient of phenotypic appearance of first episodes of Graves' hyperthyroidism and exposure to environmental factors in relation to genotypes. The study might well be representative for the whole Dutch adult population of Caucasian patients with Graves' hyperthyroidism, because we included consecutive patients originating from nine hospitals throughout The Netherlands; almost all hyperthyroid patients in The Netherlands are treated by hospital-based specialists. The frequencies of the various genotypes are in good accordance with literature data, lending further validity to our study findings.

A limitation of our study is that we did not assess all presently known susceptibility genes, not to speak of the many more unknown genotypes which must be involved in Graves' disease. We restricted ourselves, however, to genotypes that have been widely studied and whose functional significance is to a certain extent understood. The main limitation in our view is the still limited sample size, which is a severe drawback especially in the genderspecific analysis. Trends observed in males might very well become significant with a larger sample size.

\section{Concluding remarks}

The number of G-alleles in the SNP CTLA4 49A/G and, to a lesser extent, in CTLA4 CT60 is dose-dependently associated with younger age at diagnosis of Graves' hyperthyroidism and less exposure to stress. This was not observed for polymorphisms of HLA and PTPN22. The divergent effects of the various genetic variants may have emerged not by chance: the attributable fraction (that is a measure of the proportion of the risk conferred) for CTLA4 SNPs in autoimmune thyroid disease is around $25 \%$, one of the highest known for any gene in a complex disorder (31). Thus, any inverse relationship between frequencies of susceptibility alleles and exposure to stress is likely more easily detected in CTLA4 than in other genes. The data support the hypothesis that subjects with genetic susceptibility to Graves' disease might require less exposure to environmental factors to get the disease. Gender-specific analysis was hindered by limited sample size, especially in males. Nevertheless, males with HLA linkage disequilibrium had more severe hyperthyroidism which was not observed in females, and the association of G-alleles in the SNP CTLA4 49A/G with younger age and less stress was preserved in males but not in females. Thus, the role of susceptibility genes might be greater and the role of environmental factors might be smaller in males compared with females.

\section{Declaration of interest}

The authors declare that there is no conflict of interest that could be perceived as prejudicing the impartiality of the research reported.

\section{Funding}

This research did not receive any specific grant from any funding agency in the public, commercial or not-for-profit sector.

\section{Acknowledgements}

We gratefully thank the participating physicians for their collaboration in this study: Dr N Smit (Academic Medical Center, University of Amsterdam, Amsterdam), Dr A B Arntzenius (Spaarne Ziekenhuis, Hoofddorp), Dr C B Brouwer (Onze Lieve Vrouwe Gasthuis, Amsterdam), Dr J Derksen (Medisch Spectrum Twente, Enschede), Dr M J M Diekman and Dr M N Gerding (Ziekenhuis Deventer, Deventer), Dr V E A Gerdes (Slotervaartziekenhuis, Amsterdam), Dr W E de Graaff (Tergooiziekenhuizen, Blaricum), Dr R Heijligenberg (Ziekenhuis Gelderse Vallei, Ede), and Dr A F Muller (Diakonessenhuis, Utrecht). We would like to thank Ms E M Johannesma for all laboratory measurements.

\section{References}

1 Hemminki K, Xinjun L, Sundquist J \& Sundquist K. The epidemiology of Graves' disease: evidence of a genetic and an environmental contribution. Journal of Autoimmunity $20103 \mathbf{3 4}$ J307-J313. (doi:10.1016/j.jaut.2009.11.019)

2 Effraimidis G, Strieder TGA, Tijssen JGP \& Wiersinga WM. Natural history of the transition from euthyroidism to overt autoimmune hypo- or hyperthyroidism: a prospective study. European Journal of Endocrinology 2011164 107-113. (doi:10.1530/EJE-10-0785)

3 Brix TH, Christensen K, Holm NV, Harvald B \& Hegedus L. A population based study of Graves' disease in Danish twins. Clinical Endocrinology 199848 397-400. (doi:10.1046/j.1365-2265. 1998.00450.x)

4 Brix TH, Kyvik KO, Christensen K \& Hegedus L. Evidence for a major role of heredity in Graves' disease - a population based study of two Danish twin cohorts. Journal of Clinical Endocrinology and Metabolism 200186 930-934. (doi:10.1210/jc.86.2.930)

5 Ringold DA, Nicoloff JT, Kesler M, Davis H, Hamilton A \& Mack T. Further evidence for a strong genetic influence on the development of autoimmune thyroid disease: the California Twin Study. Thyroid 200212 647-653. (doi:10.1089/105072502760258613)

6 Brix TH \& Hegedus L. Twin studies as a model for exploring the aetiology of autoimmune thyroid disease. Clinical Endocrinology 201276 457-464. (doi:10.1111/j.1365-2265.2011.04318.x)

7 Vos XG, Smit N, Endert E, Tijssen JGP \& Wiersinga WM. Frequency and characteristics of TBII-seronegative patients in a population with untreated Graves' hyperthyroidism: a prospective study. Clinical Endocrinology 200869 311-317. (doi:10.1111/j.13652265.2008.03192.x)

8 Perez C, Scrimshaw NS \& Munoz JA. Technique of endemic goitre surveys. Monograph Series of the World Health Organization 196044 369-383. 
9 Klein I, Trzepacz PT, Roberts M \& Levey GS. Symptom rating scale for assessing hyperthyroidism. Archives of Internal Medicine 1988 148 387-390. (doi:10.1001/archinte.1988.00380020131018)

10 Vos XG, Smit N, Endert E, Brosschot JF, Tijssen JGP \& Wiersinga WM. Age and stress as determinants of the severity of hyperthyroidism caused by Graves' disease in newly diagnosed patients. European Journal of Endocrinology 2009160 193-199. (doi:10.1530/EJE-08-0573)

11 van de Willige G, Schreurs P, Telligen B \& Zwart E. Het meten van "life events": Vragenlijst Recent Meegemaakte Gebeurtenissen. Nederlands Tijdschrift voor Psychologie en Haar Grensgebieden 1985 40 1-19.

12 Kanner AD, Coyne JC, Schaefer C \& Lazarus RS. Comparison of two modes of stress measurements: daily hassles and uplifts versus major life events. Journal of Behavioral Medicine 1981 4 1-39. (doi:10.1007/BF00844845)

13 Vingerhoets AJJM, Jeninga AJ \& Menges IJ. The measurement of daily hassles and chronic stressors: the development of the Everyday Problem Checklist (EPCL). Gedrag \& Gezondheid 198917 10-17.

14 Watson D, Clark LA \& Tellegen A. Development and validation of brief measures of positive and negative affect: the PANAS scales. Journal of Personality and Social Psychology 198854 1063-1070. (doi:10.1037/0022-3514.54.6.1063)

15 Wiersinga WM \& Chopra IJ. Radioimmunoassay of thyroxine $\left(\mathrm{T}_{4}\right)$, $3,5,3^{\prime}$ triiodothyronine $\left(\mathrm{T}_{3}\right), 3,3^{\prime}, 5^{\prime}$-triiodothyronine (reverse $\mathrm{T}_{3}$, $\mathrm{rT}_{3}$ ), and 3,3'-diiodothyronine $\left(\mathrm{T}_{2}\right)$. Methods in Enzymology 1982 84 272-303. (doi:10.1016/0076-6879(82)84024-X)

16 Ban Y, Concepcion ES, Villanueva R, Greenberg DA, Davies TF \& Tomer Y. Analysis of immune regulatory genes in familial and sporadic Graves' disease. Journal of Clinical Endocrinology and Metabolism 2004 894562-4568. (doi:10.1210/jc.2003-031693)

17 Velaga MR, Wilson V, Jennings CE, Owen CJ, Herington S, Donaldson PT, Ball SG, James RA, Quinton R, Perros P \& Pearce SH. The codon 620 tryptophan allele of the lymphoid tyrosine phosphatase (LYP) gene is a major determinant of Graves' disease. Journal of Clinical Endocrinology and Metabolism 200489 5862-5865. (doi:10.1210/jc.2004-1108)

18 Zhu XL, Du T, Li JH, Lu LP, Guo XH, Gao JR, Gou CY, Li Z, Liu Y \& $\mathrm{Li} \mathrm{H}$. Association of HLA-DQB1 gene polymorphisms with outcomes of HBV infection in Chinese Han population. Swiss Medical Weekly 2007137 114-120.

19 Pera C, Delfino L, Longo A, Pistillo MP \& Ferrara GB. Novel associations among HLA-DQA1 and -DQB1 alleles, revealed by high-resolution sequence-based typing (SBT). Tissue Antigens 200055 275-279. (doi:10.1034/j.1399-0039.2000.550313.x)

20 Albis-Camps M \& Blasczyk R. Fluorotyping of HLA-DRB by sequence-specific priming and fluorogenic probing. Tissue Antigens 199953 301-307. (doi:10.1034/j.1399-0039.1999.530312.x)

21 Weetman AP. The genetics of autoimmune thyroid disease. Hormone and Metabolic Research 200941 421-425. (doi:10. 1055/s-0029-1214415)

22 Tomer Y. Genetic susceptibility to autoimmune thyroid disease: past, present, and future. Thyroid 201020 715-725. (doi:10. 1089/thy.2010.1644)

23 Huber A, Menconi F, Corathers S, Jacobson EM \& Tomer Y. Joint genetic susceptibility to type 1 diabetes and autoimmune thyroiditis: from epidemiology to mechanisms. Endocrine Reviews 200829 697-725. (doi:10.1210/er.2008-0015)

24 Heward JM, Allahabadia A, Daykin J, Carr-Smith J, Daly A, Armitage M, Dodson PM, Sheppard MC, Barnett AH, Franklyn JA \& Gough SCL. Linkage disequilibrium between the human leukocyte antigen class II region of the major histocompatibility complex and Graves' disease: replication using a population casecontrol and family-based study. Journal of Clinical Endocrinology and Metabolism 199883 3394-3397. (doi:10.1210/jc.83.10.3394)

25 Allahabadia A, Heward JM, Nithiyananthan R, Gibson SM, Reuser TT, Dodson PM, Franklyn JA \& Gough SC. MHC class II region, CTLA4 gene, and ophthalmopathy in patients with Graves' disease. Lancet 2001358 984-985. (doi:10.1016/ S0140-6736(01)06125-6)
26 Vaidya B, Imrie H, Perros P, Dickinson J, McCarthy MI, KendallTaylor P \& Pearce SHS. Cytotoxic T lymphocyte antigen-4 (CTLA4) gene polymorphism confers susceptibility to thyroid-associated orbitopathy. Lancet $1999 \mathbf{3 5 4}$ 743-744. (doi:10.1016/S01406736(99)01465-8)

27 Bednarczuk T, Hiromatsu Y, Fukutani T, Jazdzewski K, Miskiewicz P, Osikowska M \& Nauman J. Association of cytotoxic T-lymphocyte-associated antigen-4 (CTLA-4) gene polymorphism and non-genetic factors with Graves' ophthalmopathy in European and Japanese populations. European Journal of Endocrinology 2003148 13-18. (doi:10.1530/eje.0.1480013)

28 Petrone A, Giorgi G, Galgani A, Alemanno I, Corsello SM, Signore A, di Mario U, Nistico L, Cascino I \& Buzzetti R. CT60 Single nucleotide polymorphisms of the cytotoxic T-lymphocyteassociated antigen-4 region is associated with Graves' disease in an Italian population. Thyroid 200515 232-238. (doi:10.1089/ thy.2005.15.232)

29 Bicek A, Zaletel K, Gaberscek S, Pirnat E, Krhin B, Stopar TG \& Hojker S. 49A/G and CT60 polymorphisms of the cytotoxic T-lymphocyte-associated antigen- 4 gene associated with autoimmune thyroid disease. Human Immunology 200970 820-824. (doi:10.1016/j.humimm.2009.06.016)

30 Skorka A, Bednarczuk T, Bar-Andziak E, Nauman J \& Ploski R. Lymphoid tyrosine phosphatase (PTPN22/LYP) variant and Graves' disease in a Polish population: association and gene dose-dependent correlation with age of onset. Clinical Endocrinology 200562 679-682. (doi:10.1111/j.1365-2265.2005. 02279.x)

31 Kavvoura FK, Akamizu T, Awata T, Ban Y, Chistiakov DA, Frydecka I, Ghaderi A, Gough SC, Hiromatsu YPloski R et al. Cytotoxic T-lymphocyte associated antigen 4 gene polymorphisms and autoimmune thyroid disease: a meta-analysis. Journal of Clinical Endocrinology and Metabolism 200792 3162-3170. (doi:10.1210/jc.2007-0147)

32 Chong KKL, Chiang SWY, Wong GWK, Tam POS, Ng T-K, Hu Y-J, Yam GHF, Lam DSC \& Pang C-P. Association of CTLA-4 and IL-13 polymorphisms with Graves' disease and ophthalmopathy in Chinese children. Investigative Ophthalmology and Visual Sciences 200849 2409-2415. (doi:10.1167/iovs.07-1433)

33 Vos XG, Smit N, Endert E, Tijssen JGP \& Wiersinga WM. Variation in phenotypic appearance of Graves' disease: effect of genetic anticipation and duration of complaints. European Journal of Endocrinology 2009161 113-118. (doi:10.1530/EJE-08-0991)

34 Manji N, Carr-Smith JD, Boelaert K, Allahabadia A, Armitage M, Chatterjee VK, Lazarus JH, Pearce SH, Vaidya B, Gough SC \& Franklyn JA. Influence of age, gender, smoking, and family history on autoimmune thyroid disease. Journal of Clinical Endocrinology and Metabolism 200691 4873-4880. (doi:10.1210/jc.20061402)

35 Bednarczuk T, Gopinath B, Ploski R \& Wall JR. Susceptibility genes in Graves' ophthalmopathy: searching for a needle in a haystack? Clinical Endocrinology 200767 3-19. (doi:10.1111/j.1365-2265. 2007.02854.x)

36 Monroe SM. Major and minor life events as predictors of psychological distress: further issues and findings. Journal of Behavioral Medicine 19836 189-205. (doi:10.1007/BF0084 5380)

37 Effraimidis G, Brosschot JF, Tijssen JGP \& Wiersinga WM. Agedependent changes in recent life events and daily hassles in a cohort of healthy women. In: Effraimidis G. Early stages of thyroid autoimmunity. Follow-up studies in the Amsterdam AITD cohort, pp 83-95. PhD Thesis 2012. University of Amsterdam.

Received 28 July 2012

Revised version received 2 September 2012

Accepted 11 September 2012 